\title{
Study Protocol Preparation for Randomized Controlled Trials: Recommendations and Protocol Recording
}

\author{
Randomize Kontrollü Çalışmalar için Protokol Hazırlama: Öneriler ve Protokol \\ Kaydı
}

(D) Ayşe DAĞISTAN AKGÖZ1', iD Zeynep ÖZER²

${ }^{1}$ Akdeniz University Faculty of Nursing, Department of Public Health Nursing, Antalya, Turkey

${ }^{2}$ Akdeniz University Faculty of Nursing, Department of Medical Nursing, Antalya, Turkey

\begin{abstract}
The World Health Organization (WHO) considers the registration of the study protocol as the publication of an internationally recognized set of information on the design, conduct, and management of clinical trials. Writing a detailed study protocol with all the correct and necessary steps is an important step before starting randomized controlled trials. WHO says that study protocols should be included in a standardized registration system and published on a publicly accessible website. From an ethical point of view, the Helsinki Declaration emphasizes that study protocols should be registered in a public database. In addition, before the implementation process of the RCTs has started, obtaining the registration number (protocol ID) in public databases has become an important necessity for the studies to be published in quality journals. The purpose of this review is to review, consider recommendations and provide guidance for protocol registration during protocol preparation, which is the most important stage of a correctly planned RCT process. It is seen that the culture of planning and adhering to this protocol has not yet become widespread in the researchers in our country as they begin the RCT process, according to the principles of the study protocol preparation. It is thought that the information in this review will guide the researchers at this point.
\end{abstract}

Keywords: Study protocol, clinical trials, randomized controlled study, nursing

\section{ÖZ}

Dünya Sağlık Örgütü (DSÖ), çalışma protokolü kaydını, klinik çalışmaların tasarımı, yürütülmesi ve yönetimi ile ilgili uluslararası kabul görmüş bir bilgi dizisinin yayınlanması olarak kabul etmektedir. Doğru ve gerekli tüm basamakları içeren ayrıntılı bir çalışma protokolü yazmak, randomize kontrollü çalışmalara (RKÇ) başlamadan önce önemli bir adımdır. DSÖ çalışma protokollerini standartlara uygun bir kayıt sisteminde yer alması ve bu bilgilerin herkes tarafından erişilebilen bir web sitesinde yayınlanması gerektiğini söylemektedir. Etik açıdan bakıldığında Helsinki Bildirgesi'de çalışma protokollerinin halka açık bir veri tabanında kayıtlı olması gerektiğini vurgulamaktadır. Ayrıca hazırlanan protokollerin RKÇ’nin uygulama süreci başlamadan önce uluslararası veri tabanlarında kayıt edilmesi ve kayıt numarasının (protokol ID) alınması, çalışmaların kaliteli dergilerde yayına dönüşmesi için oldukça önemli bir zorunluluk haline gelmiştir.

Bu derlemenin amacı, kanıt değeri yüksek, doğru planlanmış bir RKÇ sürecinin en önemli aşaması olan protokol hazırlama sırasında, dikkate edilmesi gereken noktaları gözden geçirmek, öneriler vermek ve protokol kaydı için rehberlik sağlamaktır. Ülkemizdeki araştırmacılarda RKÇ sürecine başlarken, çalışma protokolü hazırlama ilkelerine göre çalışmalarını planlama ve bu protokole bağlı kalarak sürdürme kültürünün henüz yaygınlaşmadığı görülmektedir. $\mathrm{Bu}$ derlemede yer alan bilgilerin araştırmacılara bu noktada rehberlik ederek yol göstereceği düşünülmektedir.

Anahtar Sözcükler: Çalışma protokolü, klinik araştırmalar, randomize kontrollü çalışma, hemşirelik

Address for Correspondence: Ayşe DAĞISTAN AKGÖZ, Akdeniz University Faculty of Nursing,

Department of Public Health Nursing, Antalya, Turkey

E-mail: ayse.dgstn1@gmail.com ORCID ID: orcid.org/0000-0002-2933-3402 


\section{Introduction}

Evidence is information that decision-makers in the health care system can reach, based on a scientific assessment of the practice. It is also a tool that can be used to make sure patients receive the best care available $(1,2)$. Evidence- based practice (EBP) is the process of using the best available evidence to support clinical decisions $(3,4)$. It is also defined as integrating the best research evidence obtained by systematic research into personal experience, clinical decision-making ability obtained by clinical practice, and patient values and preferences $(5,6)$.

Evidence-based nursing is a process in which the evidence obtained from scientific research is critically evaluated with the participation of the patient according to status, preferences, and availability of resources of patients and healthy individuals to assure the provision of best nursing care (5). The purpose of EBP is to enable nurses to enrich their clinical training and experience with up-to-date research. EBP enables nurses to learn from many researches, gain knowledge and EBP skills that exist in nursing and enables them to research, evaluate and practice literature in the clinic. It has been reported that experimental studies have increased in the last 20 years and that more than half $(67 \%)$ of these studies are randomized controlled trials (RCT) (7). RCTs are trials conducted to assess the effects of one or more interventions on individuals or groups. It can also be called interventional trials. These interventions include drugs, cell and other biological products, surgical procedures, radiological procedures, devices, behavioral treatments, changes in care process, and preventive care (8). The importance of RCTs in terms of nursing is that these trials provide the opportunity to draw causal conclusions that will help to demonstrate the effectiveness of the interventions used by nurses. In order to achieve these results, the effectiveness of the initiatives must be demonstrated in a certain system. The synthesis of research evidence using systematic and rigorous methods has become an important feature of evidence-based medicine. It is very important to work with RCT protocols that determine the effectiveness of the intervention to create this systematics (9).

In order to implement EBPs, it is necessary to develop the skills of nurses to critically evaluate research and to establish a culture of basing their practice on scientific knowledge $(10,11)$. Nurses need to know and evaluate the levels of evidence so that EBPs can be transferred to them. Evidence levels reflect how strong the method of studies is (11). Gray and Chambers (12) classified the power of evidence into five categories. Various systems have been developed for the grading of evidence, and evidence and recommendation level classifications adopted by the Joanna Briggs Centre are used for the evaluation of evidence levels in nursing (13). According to the evidence level classification, the strongest evidence comes from at least one systematic review and meta-analysis which are based on well-designed RCTs (14). In evaluating the effectiveness of the initiative, RCT is considered to be the best research design. RCTs shown as evidential source of information provide second level of evidence in making decision for interventions and are the basic source for systematic reviews and meta-analyses which are accepted to be the first level of evidence for interventions (15). A meta-analysis is a quantitative analysis of the findings of the researches involved in the systematic review using statistical analysis techniques (16). Therefore, the main purpose of systematic review and meta-analysis is to synthesize the results of numerous researches on a particular subject and present the most accurate evidence to health professionals. In these studies, synthesis is mostly performed using the results obtained from RCTs (17). It is very important that RCTs are based on a document called a protocol, detailing the rationale, proposed methods and organization of the intervention (18).

It is possible for nurses to benefit the individuals they care for by using the evidence obtained from the RCTs, if the trials are welldesigned and implemented, reported openly and transparently. A well-prepared study protocol is needed to ensure that RCTs, which are a type of clinical research with a high level of evidence, have the chance to be based in clinical practice and directly utilized in decision-making (19). Furthermore, the quality of the evidence obtained from the RCTs depends on the detailed planning of each phase of the study, and the way to obtain these details is through the preparation of a well-planned study protocol (20).

The working protocols prepared with insufficient methodological approach can have high scientific value and appear to be excellent from a theoretical point of view. However, when the study is started, there may be some deficiencies, glitches and inappropriate points. These deficiencies may include who the participants are, which Initiative is targeted, how the participants respond to the initiative is measured, and financial and expert support (21). Proper development, evaluation and implementation of clinical trial protocols is of great importance in avoiding these deficiencies $(22,23)$.

The study protocol is a document that defines the objectives, design, methodology, statistical evaluation and organization of the work to be performed (24). The protocol is a resource that clearly states the logic and structure behind a research project (25). According to another definition, the study protocol is a document that describes each step of the research and answers questions on issues such as what goals the study will achieve, how much power it has (26). In addition, the study protocol demonstrates the guidelines needed to carry out the research. A clinical trial protocol involves processes such as planning, conducting, reporting and transferring the study to practice. A well-written protocol allows evaluation of scientific, ethical and safety issues such as suitability of the study before the study begins, execution of the study, and implementation of the results after the study is completed (27).

It is seen that the culture of planning their study according to the principles of study protocol preparation and continuing their study by adhering to the protocol have not yet become widespread in nursing researchers. A study published in a nursing journal showed that more than two-thirds of the studies 
published between the years 2011-2016 were not registered and that $54 \%$ of them were recorded after the study was initiated. It was also reported that whole study protocol was published in only $9 \%$ of the published studies and that vast majority of the published studies lacked of whole study protocol (28). These rates raise the importance of a guideline on the subject. In line with this information, it is thought that the researchers in the field of nursing have insufficient awareness of the importance of preparing a working protocol when starting a RCT. Although preparing a working protocol is a new approach in Turkey especially in the field of nursing, there are hardly any resources that can provide guidence in this regard. In addition, it has become a very important necessity to make registration in the international databases and to take protocol ID before implementation process of the RCT is started, for the studies to be published in quality journals in the future.

The purpose of this review is to increase the level of knowledge at the point of preparing and recording protocols by increasing the awareness of researchers in the field of nursing. In addition, it is thought that this review will provide researchers with guidance on making recommendations and recording the protocol by reviewing the points to be considered during the preparation of the protocol, which is the most important stage of a properly planned RCT process with high evidential value.

\section{Study Protocol Registration, Aims and Benefits}

The World Health Organization (WHO) recognizes the study protocol register as the publication of an internationally recognized series of information on the design, conduct and management of clinical trials. Details about the study are recorded in a registration system that complies with WHO standards and this information is published on a publicly accessible website (29). One of the most important journals in the field of nursing recommends that non-registered RCTs should not be published and that the authors' work could be recorded retrospectively, but that an explanation should be made about the cause. They also stated that it was ideal for the authors to publish the study protocols in a peer-reviewed journal as a full text (28). To register the working protocol in web-based databases means to obtain registration in a way. These registrations involve both the ethical and scientific aspects of the study. At the same time, the registrations provide an ethical function in ensuring that everyone is informed about ongoing and previous work. Many groups including the International Committee of Medical Journal Editors (ICMJE) argue that registrations should be managed by a non-profit organization and free for both registrars and users. Records also contribute to researchers, journal editors, and referees in the context of understanding research results (30).

It is also accepted as a scientific, ethical and moral responsibility. The Declaration of Helsinki states that "every clinical trial must be registered in a public database before the first participant is included in the study." The objectives of a study protocol are summarized below.

\section{Objectives of a study protocol}

$\checkmark \quad$ Raising the question to be investigated and clarifying its importance,

$\checkmark \quad$ Gather available information and discuss the efforts of other researchers working on relevant questions (literature review),

$\checkmark$ Formulating hypothesis and goals,

$\checkmark$ Clarify ethical considerations and obtain ethical approval,

$\checkmark$ Propose the methodology necessary to solve the question and achieve the goals,

$\checkmark$ Discuss requirements and limitations for achieving goals,

$\checkmark$ Provide funding for the current study,

$\sqrt{ }$ To ensure that all working team members are in the same denominator in terms of expectation and contribution (26).

The benefits of registering the working protocols are summarized below.

\section{Benefits of study protocol registration}

- Shows what to do by explaining the necessary points in the study and how it is carried out.

- Allows the researcher to plan and study the steps of the project.

- Serves as a guide throughout the research.

- Speeds up time and budget estimates.

- Explains participants' suitability, duration of study, drugs and related tests (31).

- Makes it easier to identify ongoing clinical trials and identify gaps in clinical trials.

- Knowledge of the study protocol makes it easier for researchers and potential participants to participate in the study.

- Enables researchers and health care practitioners to identify research they may be interested in, and to collaborate more effectively among researchers.

- Referees in the relevant database who control the data as part of the registration process identify potential problems early in the research process, enabling improvement in the quality of clinical trials.

- Journal editors and referees can determine whether the study protocol given to the journal meets the protocol design described in the first registration.

- In addition, it allows journal editors to review ongoing and previously unpublished research on the same topic (32-34).

\section{Study Protocol Preparation Steps and Format}

One of the most important stages of working protocol preparation is to obtain a protocol registration number. In order to obtain this registration number, the required information must be entered into the system of the database to be registered after preparing the working protocol in the appropriate format and the compliance of the research methodology must be confirmed through the process of refereeing in the system. In order to present the required information in these databases, it is important to prepare the study protocol in an accurate and valid format for each database. One of the most important and valid of these formats is the study protocol preparation format proposed by the WHO $(29,33,34)$. 
The key points of the protocol are that it contains the rationale for why the study is necessary and the detailed plan of the study (25). Therefore, the most difficult stage of conducting a research project is the preparation of a short but comprehensive document (protocol) that clearly outlines the project. The protocols prepared should be accurate, easy to read and free of typos.

It is important to understand the steps in developing a research protocol to accomplish what is planned and achieve reliable results. The extra time spent writing a good protocol will help with the analysis as well as prevent errors at a later stage. If the protocol is poorly prepared or it is not followed, there will be little chance of getting the expected results from the project $(31,35)$.

The format of the study protocol proposed by the WHO in Table 1 is capable of guiding researchers to prepare a good protocol. This table contains suggestions and tips for both the study protocol proposed by the WHO and all study protocol formats available to all researchers. According to the format proposed by the WHO, the study protocols consist of two parts. This table lists suggestions and tips for each section and subsections $(20,24,25,31,33,34,36)$. A similar format is summarized in Table 2 according to the information obtained from more recent references.

\section{Randomized Controlled Study Protocol Preparation Guidelines}

RCTs which are transparent, well-designed, well-managed, and based on a good protocol in terms of providing solid evidence, provide solid evidence for use in patient care and health policy decisions. Therefore, careful assessment of the quality of the study is needed before relying on the evidence that RCT provides (37). To make this assessment, the CONSORT (Consolidated Standards of Reporting Trials) report is widely used around the world as a guide for the development of registration of RCTs (38).

Table 1. Study protocol preparation format, tips and suggestions

Part 1

\section{Project Summary}

\section{General information}

- Protocol headline, protocol identification (ID) number and date

- Name and address of sponsor/funder

- Names and titles of the researchers responsible for conducting the research; addresses and telephone numbers and the responsibilities of each researcher

- Names and addresses of clinical laboratory (laboratories) and other medical and/or technical department(s) and/or institutions involved in the research

\section{Introduction and purpose \\ References}

References can also be listed at the end of Part 1.
Tips and suggestions

$\checkmark$ Like the summary of a research article, the project summary should be no more than 300 words and no more than one page (font size 12, single space).

$\checkmark$ Preferably on a separate page, it should outline all key elements of the protocol, e.g. rationale, purposes, methods, populations, timeframe and expected outcomes.

$\sqrt{ }$ Title is one of the most important features of the protocol. Because it attracts potential readers. Therefore, it should be short and in the way that addresses the problem. The main objective should be clear, convey the main objective of the research and indicate the target audience. It should convey information about the subject in a few words, provide information about the research area and should be in such a way as not to exceed $12-15$ words. The title should be followed by another short title.

$\sqrt{ }$ The research protocol must start with the description of the person who will coordinate the entire study, e.g. all details of the main researcher must be reported in the first paragraph. This will allow each participant to know who to contact in case of doubt or criticality during research.

$\checkmark$ A protocol must be administered by a principal investigator.

$\checkmark$ The health status of the participants should be checked regularly by members of the research team to ensure the safety and effectiveness of the study.

$\checkmark$ If the study is approved by the Ethics Committee, it would be appropriate to include the decision number of the Ethics Committee.

$\checkmark$ The introduction of the project should reflect the essence of the study and direct readers directly to the subject. Attention should be paid to the positive and negative aspects and limitations of the studies cited in the introduction.

$\checkmark$ The introduction should be concluded by explaining how the current study will benefit society.

$\sqrt{ }$ It should include the latest publications in the field and the title of the study should be selected only after the literature review is completed and gaps in the field to be studied are identified.

$\checkmark$ It should not be more than two pages, reducing the number of articles cited to less than 20 would probably be good practice.

$\sqrt{ }$ It should briefly answer the importance of the subject, the gaps in the literature, the purpose of the study and its benefits to society.

$\sqrt{ }$ The research question must be explained in a conclusive and concise way. Because the research question will be the basis of the study design.

$\checkmark$ The problem being addressed must be clear to readers to be able to properly understand its true meaning. The information involving size and frequency of the problem, the geographical areas affected, ethnic and gender factors, etc. should be included. 


\section{Table 1 contiuned}

$\sqrt{ }$ The objectives should be clearly stated. These should be limited to what is intended to be achieved in the study and should be determined as a result of the literature review. Objectives must be simple and specific.

\section{Aims and objectives of the study}

\section{Study design}

The scientific integrity of the study and the reliability of the study data depend heavily on the study design and methodology.

\section{Methodology}

The methodology section is the most important part of the protocol. The methodology reveals that the hypothesis will be confirmed or rejected. It also provides a comprehensive strategy for achieving goals (27).

\section{Study population (sample)}

Sample size

Data collection methods and tools used

\section{Management of the study}

\section{Strengths and limitations}

\section{Safety considerations}

$\checkmark$ Goals are broad statements that lead to purpose. After the expression of the primary goal, secondary goals can be mentioned.

$\checkmark$ More than 4-5 goals should be avoided in order not to reduce the accuracy of the project when determining the objective. It would be appropriate to use verbs as "to show", "to evaluate", "to verify", "to improve", "to reduce" and "to compare".

$\sqrt{ }$ The design of the study should include information about the type of study, the research community or sampling.

$\checkmark$ It should include information about participants (inclusion and exclusion criteria, polling criteria, etc.) and should include information such as the expected duration of the study.

$\sqrt{ }$ Explanation should be given about why the design is chosen. Methods to collect and analyze data should be explained.

$\sqrt{ }$ It should contain detailed information about interventions to be made, procedures to be used, precautions to be taken, observations to be made, laboratory examinations to be done, etc.

$\checkmark$ The intervention/drug/device being tested must be explained in detail.

$\checkmark$ Standardized or documented procedures/techniques must be explained. In the tools to be used for collecting information (surveys, guides, observation report forms, case report forms, etc.) should be introduced in detail.

$\checkmark$ In the case of a randomized controlled trial, additional information about the process of randomization and blinding, and identification of the inclusion and exclusion criteria of individuals for a part or all of the study is required.

$\sqrt{ }$ The study design must be shown in detail, along with all procedures and timing, using a graphic outline and a flow diagram.

$\checkmark$ Detailed information about all aspects of sample selection procedure and sample size calculation should be provided.

$\checkmark$ Inclusion to sampling, exclusion from sampling and continuation criteria must be specified.

$\checkmark$ The process of blinding and randomization should be explained in detail.

$\checkmark$ Detailed explanation of how the sample size is calculated is suggested for economic and ethical reasons.

$\checkmark$ The randomization that will be used to obtain a representative sample for your target population should be mentioned.

$\checkmark$ Details on "informed consent " should also be stated.

$\checkmark$ Data collection tools may include retrospective data (medical records), questionnaires, interviews (structured, semi-structured) laboratory tests and clinical examination.

$\checkmark$ The definition of the data collection tools used, the tools used in data collection and the methods used to test the validity and reliability of the device should be explained.

$\checkmark$ By preparing a work flow plan, a draft of all the steps to be carried out according to the planned timescale should be laid out. Making this flow plan in accordance with this timeline will ensure organization while implementing the study.

$\checkmark$ The team members (researchers, assistants, lab technicians, etc.) involved in the study or collecting data should be properly trained.

$\checkmark$ Talking about the strengths and limitations of the study is important to prevent unnecessary use of resources and to indicate what results may or may not be achieved.

$\checkmark$ The safety of its participants during research is the most important. The safety aspects of the research should always be kept in mind and the information presented in the protocol should be provided on how to ensure the safety of the research participants.

$\checkmark$ The research protocol should clearly state what will be followed up and for how long it will be followed up in participants. 


\section{Table 1 contiuned}

$\checkmark$ This section should be written after receiving statistical advice from a statistician. The names of the statistical tests to be used, the names of the variables to be used in the analysis, and the names of the statistical analyses to be performed to evaluate the results should be listed.

Data management and statistical analysis

Quality assurance

Expected results of the study

Generalization of results and publication policy

The duration of the project

Expected issues

Management of the project

Ethical aspect

Informed consent forms

Part 2

Budget

Other support for the project

Collaboration with other researchers or research institutions

Other research activities of researchers

Financing and insurance $\checkmark$ If computer programs are to be implemented, it is important to specify the software used and its version.

$\sqrt{ }$ The protocol should provide information on how to manage data, including coding for computer analysis, monitoring and verification.

$\checkmark$ Procedures for the selected sample size, for the strength of the study, for the level of importance to be used and for incomplete or false data should be prepared.

$\sqrt{ }$ The protocol should define the quality control and assurance system based on guidelines and procedures such as the WHO-established clinical trial practice guide, SPIRIT (Standard Protocol Items: Recommendations for Interventional Trials) Checklist.

$\sqrt{ }$ The protocol should also show how the study will contribute to science, how the results will be used, and how it will affect health services, health systems or health policies.

$\sqrt{ }$ The protocol should include information about the spread of results not only in the scientific media but also to the community and participants, and for policymakers to take these results into account when setting policy.

$\checkmark$ The publishing policy should be openly discussed. (For example, who will lead publications, who will provide and organize their spread, etc.)

$\checkmark$ The protocol must specify a probable period for each phase of the project

$\checkmark$ This part should discuss issues that could prevent researchers from successfully completing their projects within the prescribed time frame and within the requested funding. It should also offer possible solutions to deal with these problems.

$\sqrt{ }$ This part must define the role and responsibility of each member of the team.

$\checkmark$ It should not be limited to providing information on how and by whom ethics approval is to be received, but also it should document issues that are likely to cause an ethics violation.

$\checkmark$ It should be stated whether the procedures to be followed are in accordance with the Helsinki Declaration.

$\checkmark$ In all cases, the study should not be initiated unless the approval of the Ethics Committee is obtained.

$\checkmark$ Researchers must also explain how they plan to obtain informed consent from research participants (the process of informed consent).

$\checkmark$ If the research involves multiple groups of individuals, for example health care workers and health care providers, it should include a separate personalized informed consent form for each group. This allows each group of participants to receive the information they need to make an informed decision.

Tips and suggestions

$\sqrt{ }$ The budget section should be written in detail of the requested funds and by indicating a rationale for each item.

$\checkmark$ This part must provide information about funding received from other funding agencies or expected fundings for this project.

$\checkmark$ It should be ensured that links to other projects are indicated and that the CVs of the responsible researcher and each researcher are indicated

$\checkmark$ The responsible researcher must list all existing research projects he or she has participated in, the source of funding for these projects, the duration of these projects, and the percentage of time spent on each.

$\checkmark$ Financing and insurance information should be disclosed if it exists.

$\checkmark$ If investigators seek financial support, all sources obtained must be listed to avoid a conflict of interest. 
Table 2. Summary of the main sections and subsections that should be included in the study protocol

\section{Name \\ Address \\ Telephone/Fax \\ E-mail}

Responsible investigator

Number of related centers (for multicenter studies)

Specify reference center

Name of the study

Protocol number (abbreviated form)

Keywords (up to 7 specific keywords)

Rationale for the research (explain with available scientific evidence supporting the research)

\section{Study design \\ Monocentric/multisentric \\ Prospective/retrospective \\ Controlled/uncontrolled \\ Open label/single blind or double blind \\ Randomized/non-randomized \\ Experimental/observational \\ Others}

Priority target

Expected results

Criteria analyzed

Basic variables

Main variables

Security variables

Visits and examinations (interventions)

Study population

Short definition of main inclusion and exclusion criteria

\section{Sample size}

Estimation of duration of study

Requested funds

Additional features

Preparing a randomized RCT protocol contains more specific details, unlike reporting RCC results. The EQUATOR web page, which contains quality control lists for each type of research, is widely preferred by researchers on this topic, and contains two guidelines for protocol preparation (39). One of these is the PRISMA-P checklist that researchers can use when preparing a systematic review protocol (40). The other is the SPRIT 2013 checklist. The SPIRIT recommendations are a guide for the authors preparing a RCT protocol. Although randomized controlled study protocols are the basis for study planning, execution, reporting and evaluation, they differ greatly in content and quality. To address this issue, SPIRIT (Standard Protocol Items: Recommendations for Interventional Trials) was published in 2013. SPIRIT provides an evidence-based list based on the substances proposed for inclusion in the RCT protocols. SPIRIT 2013 is proposed as a guide for researchers who will prepare a RCT protocol (41).

\section{Accessible Databases Where Study Protocol Can Be Registered}

The databases where the working protocol can be registered and the registration number can be obtained are quite varied. The WHO International Clinical Research Registration Platform covers all these databases and collects them all under one roof. Table 3 contains the most commonly used web addresses of these databases and information from The Who's International Clinical Trials Registry Platform (8,42-44). In the vast majority of these databases, protocols go through the process of arbitration before the registration number is given.

The databases where the working protocol can be registered and the registration number can be obtained are quite varied. The WHO International Clinical Research Registration Platform covers all these databases and collects them all under one roof. Table 3 contains the most commonly used web addresses of these databases and information for The Who's International Clinical Trials Registry Platform $(8,42-44)$. In the vast majority of these databases, protocols go through the process of arbitration before the registration number is given.

\section{Conclusion}

It is thought that the information contained in this review will guide the researchers at the point of preparing RCT protocol. With this guide, researchers will be able to understand the importance and benefits of study protocol preparation and how they should form these steps. They will also be able to access the necessary information for the registration of the study protocols they have created.

Writing a detailed protocol that contains all the correct and necessary steps is an important step before starting study. The protocol should be written simply and accurately, but clarify all aspects of the protocol. For this purpose, the use of the study protocol preparation format proposed by the WHO provides both ease in registering the protocol of the study and allows to describe the design and course of the study in detail.

From an ethical point of view, the Declaration of Helsinki also stresses that study protocols must be registered in a public database. Researchers are advised to evaluate the study protocols according to their internationally valid check lists before registering and to register the study protocols in international databases. The registration number obtained from these databases will be included in the protocol part of the study, and when researchers reach the publication stage, this condition will be used by many quality journals. A RCT based on the study protocol preparation steps will be a good source of evidence for use in EBPs and will contribute to the improvement of the quality of RCT and the increase of the value of evidence. 
Table 3. Databases in which study protocols can be registered

\begin{tabular}{|c|c|c|}
\hline Database name & Web address & Explanations \\
\hline Clinical trials & https://clinicaltrials.gov/ & $\begin{array}{l}\sqrt{ } \text { "ClinicalTrials.gov" is a database in which the results of human clinical studies } \\
\text { conducted throughout the world are recorded open to public and which is } \\
\text { supported by the United States in particular. } \\
\sqrt{ } \text { It is often preferred by researchers, while the majority of RSCs are registered in } \\
\text { this database and the registration number (protocol ID) is taken. } \\
\sqrt{ } \text { In order to become a member of this database, a password must be obtained } \\
\text { from the institution that the researcher is affiliated to by contacting the } \\
\text { administrator designated by ClinicalTrial. } \\
\sqrt{ } \text { After the protocol of the study is registered in the database, the protocol } \\
\text { registration number is given if it is considered appropriate by the referees. } \\
\sqrt{ } \text { The Australian New Zealand Clinical Trials Registry (ANZCTR) is the database in } \\
\text { which the protocol registration of clinical trials is provided. }\end{array}$ \\
\hline $\begin{array}{l}\text { The Australian New } \\
\text { Zealand Clinical Trials } \\
\text { Registry (ANZCTR) }\end{array}$ & http://www.anzctr.org.au/ & $\begin{array}{l}\sqrt{ } \text { In } 2007 \text { the ANZCTR was one of the first three trial registries to be recognised } \\
\text { by the World Health Organization International Clinical Trials Registry Platform } \\
\text { (WHO ICTRP) as a Primary Registry. The ANZCTR contributes data to the WHO } \\
\text { ICTRP, which was developed in } 2007 \text {. }\end{array}$ \\
\hline $\begin{array}{l}\text { WHO International } \\
\text { Clinical Trials Registry } \\
\text { Platform (ICTRP) }\end{array}$ & $\begin{array}{l}\text { http://apps.who.in ct/ } \\
\text { trialsearch/ }\end{array}$ & 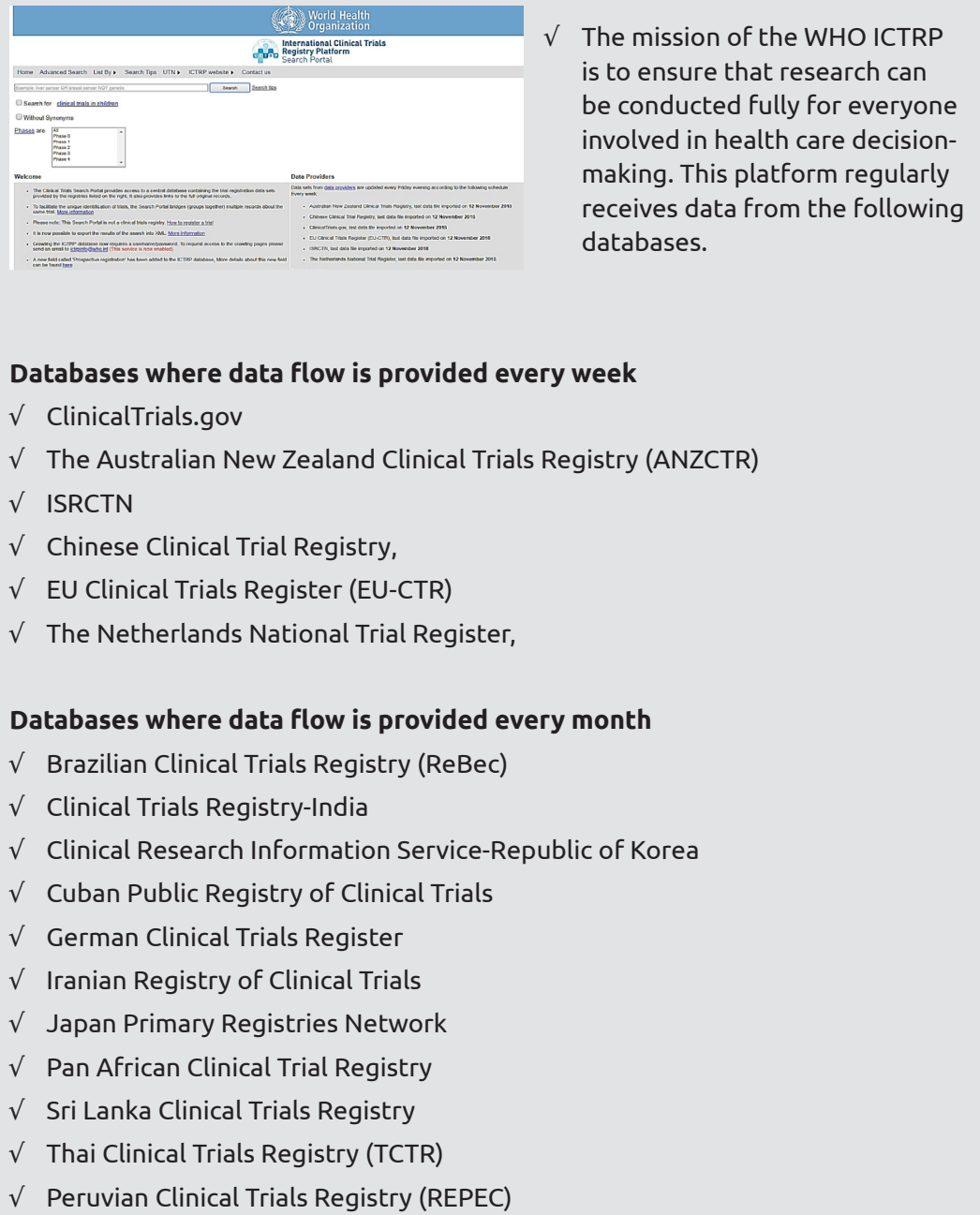 \\
\hline
\end{tabular}




\section{Ethics}

Peer-review: Internally peer reviewed.

\section{Authorship Contributions}

Concept: A.D.A., Z.Ö., Design: A.D.A., Z.Ö., Analysis or Interpretation: A.D.A., Z.Ö., Literature Search: A.D.A., Writing: A.D.A.

Conflict of Interest: No conflict of interest was declared by the authors.

Financial Disclosure: The authors declared that this study received no financial support.

\section{References}

1. Senyuva E. Hemşirelik Eğitimi ve Kanıta Dayalı Uygulamalar. Florence Nightingale Hemşirelik Dergisi 2016;24:59-65.

2. Closs S, Cheater F. Evidence for nursing practice: a clarification of the issues. Journal of Advanced Nursing 1999;30:10-7.

3. Arslan S, Şener DK, Küçük Ö. Pediatri kliniğinde çalişan hemşirelerin kanita dayali uygulamalara ilişkin görüşleri. Yildirim Beyazit Üniversitesi Hemşirelik E-Dergisi. 2016;3.

4. Kocaman G. Hemşirelikte Kanıta Dayalı Uygulama. Hemşirelikte Araştırma Geliştirme Dergisi 2006;2:61-9.

5. Scott K, McSherry R. Evidence-based nursing: clarifying the concepts for nurses in practice. Journal of clinical nursing 2009;18:1085-95.

6. Ingersoll GL. Evidence-based nursing: what it is and what it isn't. Nursing outlook 2000;48:151-2.

7. Baldi I, Dal Lago E, De Bardi S, Sartor G, Soriani N, Zanotti R, et al. Trends in RCT nursing research over 20 years: mind the gap. British journal of nursing (Mark Allen Publishing) 2014;23:895-9.

8. WHO. International Clinical Trials Registry Platform (ICTRP) 2018 [cited 2018 December 15]

9. Boden C, Bidonde J, Busch A. Gaps exist in the current guidance on the use of randomized controlled trial study protocols in systematic reviews. Journal of Clinical Epidemiology 2017;85:59-69.

10. Closs SJ, Cheater FM. Evidence for nursing practice: a clarification of the issues. J Adv Nurs 1999;30:10-7.

11. Kocaman G. Hemşirelikte Kanıta Dayalı Uygulama. Hemşirelikte Araştırma Geliştirme Dergisi 2003;2:61-9.

12. Gray J, Chambers LW. Evidence-based healthcare: how to make health policy \& management decisions. Canadian Medical Association Journal 1997;157:1598.

13. Guyatt GH, Oxman AD, Kunz R, Vist GE, Falck-Ytter Y, Schunemann HJ. What is "quality of evidence" and why is it important to clinicians? Bmj 2008;336:995-8.

14. Donaldson L. Evidence-based health care, by J A Muir Gray1997. 615-p.

15. Burns PB, Rohrich RJ, Chung KC. The levels of evidence and their role in evidence-based medicine. Plastic and reconstructive surgery 2011;128:305-10.

16. Moher D, Liberati A, Tetzlaff J, Altman DG. Preferred reporting items for systematic reviews and meta-analyses: the PRISMA statement. PLoS medicine 2009;6:e1000097.
17. Grove SK, Burns N, Gray J. The practice of nursing research: Appraisal, synthesis, and generation of evidence: Elsevier Health Sciences; 2012.

18. Association WM. Declaration of Helsinki. Ethical principles for medical research involving human subjects. http://www wma net/e/ policy/b3 htm. 2008.

19. Schulz KF, Altman DG, Moher D. CONSORT 2010 Statement: updated guidelines for reporting parallel group randomised trials. BMJ 2010;340:c332.

20. Cameli M, Novo G, Tusa M, Mandoli GE, Corrado G, Benedetto F, et al. How to Write a Research Protocol: Tips and Tricks. Journal of cardiovascular echography 2018;28:151-3.

21. Chow S-C, Liu J-p. Design and analysis of clinical trials: concepts and methodologies: John Wiley \& Sons;2008.

22. ECCRT(European Centre For Clinical Research Training). Writing Clinical Research Protocols 2016 [cited 2018 December 10].

23. DeRenzo E, Moss J. Writing clinical research protocols: Ethical considerations: Elsevier; 2005.

24. Chan A-W, Tetzlaff JM, Gøtzsche PC, Altman DG, Mann H, Berlin JA, et al. SPIRIT 2013 explanation and elaboration: guidance for protocols of clinical trials. Bmj 2013;346:e7586.

25. O’Brien K, Wright J. How to write a protocol. Journal of orthodontics 2002;29:58-61.

26. wiki.ecdc.europa. Writing a Study Protocol 2016 [cited 2018 December, 6].

27. Gonzalez CD, Bolaños R, de Sereday M. Editorial on hypothesis and objectives in clinical trials: superiority, equivalence and noninferiority. Thrombosis journal 2009;7:3.

28. Gray R, Badnapurkar A, Thomas D. Reporting of clinical trials in nursing journals: how are we doing? Journal of Advanced Nursing 2017;73:2782-4.

29. WHO. Trial Registration 2018 [cited 2018 December, 15

30. Zarin DA, Keselman A. Registering a clinical trial in ClinicalTrials. gov. Chest 2007;131:909-12.

31. Al-JunDi A, Sakka S. Protocol writing in clinical research. Journal of clinical and diagnostic research: JCDR 2016;10:ZE10.

32. Huang GD, Bull J, Johnston McKee K, Mahon E, Harper B, Roberts JN. Clinical trials recruitment planning: A proposed framework from the Clinical Trials Transformation Initiative. Contemporary Clinical Trials 2018;66:74-9.

33. WHO ICTRP. International Clinical Trials Registry Platform Searh Portal 2018 [cited 2018 December, 22]. Available from: http://apps. who.int/trialsearch/.

34. WHO. Recommended format for a Research Protocol 2018 [cited 2018 December, 15].

35. Eaton KA, Santini A. An Introduction to Research for Primary Dental Care Clinicians Part 3: Stage 5. Writing a Protocol. Primary Dental Care 2011;18:91.

36. Bhandari M, Devereaux PJ, Montori V, Cina C, Tandan V, Guyatt $\mathrm{GH}$. Users' guide to the surgical literature: how to use a systematic literature review and meta-analysis. Canadian journal of surgery Journal canadien de chirurgie 2004;47:60-7. 
37. Smith BA, Lee HJ, Lee JH, Choi M, Jones DE, Bausell RB, et al. Quality of reporting randomized controlled trials (RCTs) in the nursing literature: application of the consolidated standards of reporting trials (CONSORT). Nursing outlook 2008;56:31-7.

38. Schulz KF, Altman DG, Moher D. CONSORT 2010 statement: updated guidelines for reporting parallel group randomised trials. BMC medicine 2010;8:18.

39. equator network. Enhancing the QUAlity and Transparency Of health Research 2019 [cited 20195 May,].

40. Moher D, Shamseer L, Clarke M, Ghersi D, Liberati A, Petticrew $\mathrm{M}$, et al. Preferred reporting items for systematic review and meta- analysis protocols (PRISMA-P) 2015 statement. Systematic reviews 2015;4:1.

41. Chan AW, Tetzlaff JM, Altman DG, Laupacis A, Gotzsche PC, KrlezaJeric K, et al. SPIRIT 2013 statement: defining standard protocol items for clinical trials. Annals of internal medicine 2013;158:200-7.

42. ClinicalTrials.gov. ClinicalTrials.gov is a database of privately and publicly funded clinical studies conducted around the world 2018 [cited 2018 December,13].

43. ANZCTR. The Australian New Zealand Clinical Trials Registry 2019.

44. BMC Part of Springer Nature. ISRCTN registry 2019. 